\title{
FENOLOGIA E PRODUÇÃO DE GEMAS EM CULTIVARES E SELEÇÕES DE PESSEGUEIRO NA REGIÃO DE JABOTICABAL-SP ${ }^{1}$
}

\author{
FERNANDO MENDES PEREIRA² \& NEWTONALEX MAYER ${ }^{3}$
}

RESUMO - O cultivo do pessegueiro, nos últimos anos, vem demonstrando ser uma atividade viável tecnicamente e atrativa sob o ponto de vista econômico, na região de Jaboticabal-SP. Para que essa região se torne um novo pólo de produção de pêssegos, faz-se necessário estudos com novas cultivares e seleções locais de dupla finalidade, ampliando as opções e o período de colheita. O presente trabalho teve por objetivo estudar a fenologia e a produção de gemas das cultivares Aurora-1 e Régis e das seleções 'Jab 484' e Jab 694', na região de Jaboticabal-SP. Em dois anos de avaliações (2005 e 2006), conclui-se que: a) a cultivar Régis apresenta a maior produção de gemas floríferas por ramo misto, a maior relação entre gemas floríferas/vegetativas e o menor ciclo (entre 72 e 74 dias) dentre os genótipos estudados, sendo a única classificada como ultraprecoce; b) as seleções 'Jab 484' e 'Jab 694' apresentam ciclo mediano e comportamento fenológico idêntico, com período de colheita entre 08 e 28 de dezembro; c) A cultivar Aurora-1, quando cultivada na região de Jaboticabal-SP, apresenta relação de gemas floríferas/vegetativas próxima a 1, ciclo entre 82 e 85 dias e pode ser classificada como bem precoce.

Termos para indexação - Prunus persica (L.) Batsch, frutas de caroço, gemas floríferas, gemas vegetativas, ciclo.

\section{FENOLOGY AND BUD PRODUCTION IN PEACH TREE CULTIVARS AND SELECTIONS IN THE REGION OF JABOTICABAL, STATE OF SÃO PAULO, BRAZIL}

\begin{abstract}
The peach tree culture, in the last years, has been showing to be a viable technically and an attractive economic activity in the region of Jaboticabal, state of São Paulo, Brazil. For this region to become a new peaches' production pole, new studies are necessary using new peach cultivars and adapted genotypes with double purpose, enlarging the options and harvest period. The present research had for objective to study the fenology and bud production in 'Aurora-1' and 'Régis' peach cultivars and 'Jab 484' and 'Jab 694' peach selections in the region of Jaboticabal. In two years of evaluations (2005 and 2006), it was conclude that: a) 'Régis' cultivar presents larger bud flowers production for mixed branch, larger vegetative/flowers buds relation and smaller cycle (between 72 and 74 days) among the genotypes studied, being the only one classified as ultra precocious; b) the selections 'Jab 484' and 'Jab 694' present medium cycle and identical fenological behavior, having a harvest period between December $8^{\text {th }}$ to $28^{\text {th }}$; c) 'Aurora- 1 ' cultivar, when cultivated in the region of Jaboticabal, presents flower/vegetative bud relation near to 1, cycle between 82 and 85 days and can be classified as very precocious.
\end{abstract}

Index Terms - Prunus persica (L.) Batsch, stone fruits, flower buds, vegetative buds, cycle.

\section{INTRODUÇÃO}

A cultura do pessegueiro, classificada como sendo de clima temperado, tem apresentado expansão em área de cultivo em regiões com pouca disponibilidade de frio no inverno, especialmente no Estado de São Paulo (Cati, 1997; Barbosa et al., 2003). Essa situação deve-se principalmente ao lançamento de cultivares com pouca exigência em frio para superação da endodormência (Barbosa et al., 1997). As cultivares de pessegueiro e de nectarineira recomendadas para o cultivo no Estado de São Paulo apresentam ciclo entre a floração e a maturação dos frutos, entre $\leq 74$ dias até $\geq 181$ dias, podendo ser classificadas em ultraprecoce, bem precoce, precoce, mediana, tardia ou bem tardia (Barbosa et al., 1990).

Além da disponibilidade de cultivares adaptadas às condições de pouco frio, devem-se destacar também o desenvolvimento e o uso de tecnologias auxiliares que viabilizam a produção comercial de pêssegos nessas regiões, tais como: a irrigação por microaspersão; a aplicação da cianamida hidrogenada por ocasião da poda de produção; e a realização de duas podas anuais em cultivares de ciclo curto, sendo uma de produção (entre a segunda quinzena de maio até fins de julho) e outra de renovação (outubro-novembro). A poda de renovação faz-se necessária em regiões subtropicais e tropicais, pois provoca novo crescimento vegetativo e retarda a diferenciação das gemas para os meses de maio ou junho, período em que as temperaturas são mais favoráveis à manutenção da viabilidade do pólen e à fecundação das flores (Nienow, 1997; Pereira et al., 2002).

O baixo risco de geadas tardias, a deficiência hídrica entre abril e setembro na região de Jaboticabal (Volpe, 2000a.; Volpe 2000b.) e a lacuna existente no mercado para pêssegos precoces de alta qualidade foram elementos que despertaram para a

'(Trabalho 066-07). Recebido em : 19-03-2007. Aceito para publicação em: 06-09-2007. Apoio financeiro: FAPESP (Processo n⿳o 04/12110-6). ${ }^{2}$ Eng. Agr., Dr., Prof. Titular Voluntário do Depto. de Produção Vegetal da FCAV/UNESP. Departamento de Produção Vegetal - Via de Acesso Prof. Paulo Donato Castellane s/n, CEP 14884-900, Jaboticabal-SP. E-mail: inagrojab@yahoo.com.br ${ }^{3}$ Eng. Agr., Dr.,Pesquisador da Embrapa Clima Temperado, Rodovia BR 392, Km 78, Caixa Postal 403, Cep 96001-970, Pelostas-RS E-mail: alex@cpact.embrapa.br. 
realização de um projeto na Faculdade de Ciências Agrárias e Veterinárias (FCAV/UNESP, Câmpus de Jaboticabal), para viabilizar o cultivo comercial do pessegueiro na região de Jaboticabal-SP (Pereira et al., 2002). Entretanto, os resultados de pesquisa obtidos são consistentes e apresentam viabilidade comercial somente para a cultivar Aurora-1, apesar de já terem sido estudadas 12 cultivares de pessegueiro e de nectarineira (Pereira et al., 2002). Para que a região centro-norte do Estado de São Paulo possa consolidar-se como produtora de pêssegos de alta qualidade, faz-se necessário, entretanto, disponibilizar informações técnicas de outras cultivares ou seleções locais. Neste sentido, constatou-se que pêssegos de dupla finalidade mereceriam maiores investigações na região e que ampliariam consideravelmente a oferta, tanto em sabor, cor e acidez, como em tamanho, visando também a aumentar o período de colheita. Baseando-se em trabalho de melhoramento genético desenvolvido na região e em testes preliminares, foram eleitas para integrar este trabalho, além de 'Aurora-1' (Ojima et al., 1989), as seleções 'Jab 484' e 'Jab 694' (Salles, 1997; Salles, 2002) e a cultivar Régis (Ojima et al., 1991), a qual ainda não havia sido testada na região.

O objetivo do presente trabalho foi estudar a fenologia e a produção de gemas em cultivares e seleções de pessegueiro com potencial para a região de Jaboticabal-SP.

\section{MATERIAL E MÉTODOS}

Para a instalação do experimento, foram produzidas mudas de pessegueiro [Prunus persica (L.) Batsch] das cultivares Aurora-1 (Ojima et al., 1989) e Régis (Ojima et al., 1991), além das seleções 'Jab 484' e 'Jab 694' (Salles, 1997; Salles, 2002), por meio de enxertia de borbulhia em escudo modificado (Pereira \& Mayer, 2005). As seleções 'Jab 484' e 'Jab 694' são oriundas de seedlings da cv. Biuti de polinização aberta, selecionadas em São Carlos-SP, e testadas na região de Jaboticabal-SP, onde apresentaram potencial de cultivo e características superiores ao seu progenitor (Salles, 1997; Salles, 2002). O porta-enxerto utilizado foi a cultivar Okinawa [Prunus persica (L.) Batsch], propagada por germinação de sementes após estratificação em geladeira (Pereira \& Mayer, 2005). Durante toda a fase de viveiro, os porta-enxertos foram mantidos em sacos plásticos perfurados $(28 \times 18 \mathrm{~cm})$, contendo substrato comercial (Rendmax Citrus $\left.{ }^{\circledR}\right)$.

O experimento foi instalado na Fazenda Santa Alzira, localizada no Município de Vista Alegre do Alto-SP, distando 50 $\mathrm{km}$ de Jaboticabal-SP. A correção da acidez do solo foi feita com calagem, para elevar a saturação por bases a $70 \%$ e manter o teor de Mg no mínimo em $9 \mathrm{mmol} / \mathrm{dm}^{3}$ (Raij et al., 1996). O corretivo foi aplicado em todo o terreno e incorporado mediante aração e gradagem. As covas foram preparadas $(50 \times 50 \times 50 \mathrm{~cm})$, adotandose o espaçamento de $6 \times 4 \mathrm{~m}$. A adubação de instalação consistiu na aplicação dos seguintes produtos, por cova: $20 \mathrm{~kg}$ de esterco de bovinos curtido; 1 a 1,5 kg de superfosfato simples e $60 \mathrm{~g}$ de $\mathrm{K}_{2} \mathrm{O}$ (Pereira et al., 2002). Transcorridos 30 dias da aplicação dos fertilizantes, as mudas foram transplantadas (agosto de 2003), mantendo-se o torrão que envolve as raízes intacto. Em seguida, as hastes principais foram podadas a $50 \mathrm{~cm}$ de altura, objetivando a brotação dos ramos laterais. Foram realizados todos os tratos culturais necessários para a adequada condução das plantas, conforme recomendações de Pereira et al. (2002) para a cultura do pessegueiro na região. A poda de renovação não foi feita nas seleções 'Jab 484' e 'Jab 694' após a colheita de 2005, por apresentarem ciclo longo e por dispensarem essa prática.

A fenologia das duas cultivares e das duas seleções foi estudada em 2005 e 2006, conforme Nienow (1997). Para tanto, foi realizada a poda de produção e, em seguida, a aplicação da cianamida hidrogenada a $0,29 \%$ do ingrediente ativo (Pereira et al., 2002), anotando-se a data (DCH). Como não foi necessária a poda de renovação no final de 2005 nas seleções 'Jab 484' e 'Jab 694', a poda de produção nestas seleções necessitou ser antecipada em 17 dias em relação à 'Régis' e 'Aurora-1', em 2006. Foi assinalado o número de dias para iniciar a floração (NDIF), a partir da aplicação da cianamida hidrogenada, a data de início, plena floração e final da floração e o número de dias da floração. Para o período de colheita, foram assinalados a data de início, final e o número de dias do período. Finalmente, o ciclo de cada genótipo foi determinado com a contagem do número de dias transcorridos da plena floração até a data da metade do período de colheita.

O comprimento médio de ramos mistos foi avaliado, aproximadamente, aos 25 dias após a poda de produção e aplicação da cianamida hidrogenada, tanto em 2005 como em 2006, momento em que foi possível distinguir as gemas floríferas das vegetativas e relacionar o número de gemas com o comprimento do ramo, que havia sofrido desponte por ocasião da poda de produção (Pereira et al., 2002). Para tanto, foram marcados 20 ramos no terço mediano da planta útil de cada parcela, sendo 5 ramos em cada quadrante ao redor da planta, e tomada a medida do comprimento com auxílio de fita métrica. Em seguida, utilizando-se dos mesmos ramos marcados, procedeu-se à contagem do número de gemas floríferas e do número de gemas vegetativas por ramo, baseando-se na morfologia típica de cada uma delas (Sachs \& Campos, 1998). Posteriormente, os dados foram padronizados para serem expressos em número de gemas floríferas e número de gemas vegetativas por $30 \mathrm{~cm}$ lineares de ramo misto. A partir do número de gemas floríferas e vegetativas contidas em cada ramo misto marcado, foi calculada a relação entre essas duas variáveis por divisão.

O delineamento experimental utilizado foi de blocos ao acaso, com 4 tratamentos (cvs. Aurora-1 e Régis e seleções 'Jab 484' e 'Jab 694') e 6 repetições de 3 plantas cada (tomando-se a planta central como útil), totalizando 24 parcelas ou 72 plantas. $O$ espaçamento entre as plantas foi de $6 \times 4 \mathrm{~m}$, resultando em área total de $1.728 \mathrm{~m}^{2}$. Os dados foram submetidos à análise de variância pelo teste $\mathrm{F}$, e as médias foram comparadas pelo teste de Tukey, ao nível de $5 \%$ de probabilidade.

\section{RESULTADOS E DISCUSSÃO}

Com a aplicação da cianamida hidrogenada em 13 de julho de 2005 (Tabela 1), os quatro genótipos estudados iniciaram a floração em apenas 14 dias. Em 2006, o número de dias para o início da floração foi pouco maior nos quatro genótipos, sendo 
23 dias em 'Régis' e 18 dias para os demais (Tabela 2). Nienow (1997) verificou que, para a cultivar Aurora-1, o número de dias entre a aplicação da cianamida hidrogenada e o início da floração variou de 14 a 22 dias, em função da data de realização da poda de renovação no ano anterior.

Em 2005, o período de floração (28 dias) foi o mesmo para todos os genótipos (Tabela 1). Já em 2006, o período de floração foi menor, sendo de 21 dias para as duas cultivares e 22 dias para as duas seleções (Tabela 2). Nienow (1997) também observou que o período de floração variou de um ano para o outro na cv. Aurora-1, de 19 a 26 dias em 1995 e de 26 a 34 dias em 1996.

Com relação ao início da colheita, observou-se que o número de dias contados a partir da aplicação da cianamida hidrogenada foi praticamente o mesmo em 'Régis' (entre 97 e 101 dias) e 'Aurora-1' (100 ou 101 dias). Essa informação é importante para o planejamento do início da colheita, pois o produtor pode manipular a data da poda de produção e aplicação da cianamida hidrogenada entre 15 de maio e 31 de julho (Pereira et al., 2002), podendo escalonar a época de colheita de uma mesma cultivar, diminuindo os riscos adversos do clima. Deve-se salientar que, tanto em 2005 como em 2006, a aplicação da cianamida hidrogenada foi feita tardiamente em função do atraso no desenvolvimento dos ramos, o que, conseqüentemente, atrasou a data de início da colheita.

Para as seleções 'Jab 484' e 'Jab 694', observou-se que, em 2005, a colheita iniciou no dia 14 de dezembro, aos 154 dias após a aplicação da cianamida hidrogenada (Tabela 1). Já em 2006, o início da colheita ocorreu com maior número de dias após a aplicação da cianamida hidrogenada (175 dias) (Tabela 2). Destaca-se a potencialidade dessas seleções em função de o período de colheita encontrar-se próximo às festividades de final de ano, podendo tornar-se boas opções para aumentar a oferta de pêssegos de dupla finalidade produzidos na região, ampliando em aproximadamente 30 dias o atual período de oferta.

Foi observado que a duração do período de colheita apresenta diferenças entre os genótipos (Tabelas 1 e 2). As seleções 'Jab 484' e 'Jab 694' apresentaram menor período de colheita, sendo 14 dias em 2005 e apenas 07 dias em 2006. A cultivar 'Régis' apresentou período de colheita com duração entre 11 e 20 dias e em 'Aurora-1' foi observado o maior período, entre 17 e 30 dias. Nienow (1997) verificou períodos menores de colheita para 'Aurora-1', entre 11 e 23 dias. O conhecimento do período de colheita das cultivares e seleções também auxilia no planejamento das operações de colheita, classificação, embalagem, transporte e comercialização.

O ciclo das cultivares e seleções, considerando a data da plena floração até a metade do período de colheita, também apresentou diferenças (Tabelas 1 e 2). A cultivar Régis apresentou o menor ciclo, entre 72 e 74 dias, o que a credencia como uma cultivar bastante promissora para a região de Jaboticabal, possibilitando produzir frutos de dupla finalidade em época bem precoce. Segundo Barbosa et al. (1990), a cultivar Régis apresenta ciclo entre 93 e 98 dias em Jundiaí-SP, onde a mesma é classificada como precoce, e a maturação ocorre em outubro. Na região de Jaboticabal, pode-se constatar que o ciclo desta cultivar é reduzido em, pelo menos, 20 dias. De acordo com a classificação das cultivares em função do ciclo (Barbosa et al., 1990), 'Régis' pode ser classificada como ultraprecoce quando cultivada na região de Jaboticabal-SP, por apresentar ciclo $\leq 74$ dias.

A cultivar Aurora- 1 apresenta ciclo entre 82 e 85 dias (Tabelas 1 e 2), o que concorda com Nienow (1997), permitindo classificá-la como bem precoce, segundo critério proposto por Barbosa et al. (1990). O ciclo observado em 'Aurora-1' também é menor do que o observado em outras regiões do Estado de São Paulo, como em Jundiaí, onde o ciclo dessa cultivar varia entre 104 e 115 dias, ou mesmo em Limeira (ciclo de 95 dias), regiões onde 'Aurora-1' é classificada como precoce (Ojima et al., 1989; Barbosa et al., 1990). Dessa forma, as condições climáticas da região de Jaboticabal permitiram reduzir o ciclo e obter produção bem precoce da cv. Aurora-1 (Nienow, 1997; Pereira et al., 2002).

No presente estudo, as seleções 'Jab 484' e 'Jab 694' apresentaram ciclo idêntico, sendo 128 dias em 2005 e 149 dias em 2006. Segundo Salles (2002), 'Jab 484' apresenta 129 dias de período médio entre a florada e a colheita, enquanto, em ' $\mathrm{Jab}$ 694', o período é de 125 dias. Esses dados comprovam o menor ciclo de ambas as seleções em relação ao progenitor 'Biuti', que, na região de Jundiaí, apresenta ciclo médio de 155 dias (Barbosa et al., 1990). Por apresentarem ciclo entre 121 e 150 dias, 'Jab 484' e 'Jab 694', quando cultivadas na região de Jaboticabal, podem ser classificadas como de ciclo mediano, de acordo com a classificação proposta por Barbosa et al. (1990).

O comprimento dos ramos mistos, mensurado após a poda de produção (Tabela 3), não apresentou diferença significativa entre as cultivares e seleções, tanto em 2005 como em 2006, comprovando o uso do mesmo critério na poda e a uniformidade no desponte dos ramos.

$\mathrm{O}$ número de gemas floríferas por $30 \mathrm{~cm}$ de ramo foi semelhante entre as avaliações de 2005 e de 2006 (Tabela 3). A cultivar Régis apresentou 23,23 gemas floríferas por $30 \mathrm{~cm}$ de ramo em 2005 e 31,50 gemas floríferas por $30 \mathrm{~cm}$ de ramo em 2006, o que equivale a praticamente 1 gema de flor a cada centímetro. Esses resultados concordam com Ojima et al. (1991), que destacaram a grande produção de ramos frutíferos da cultivar e o florescimento abundante. A descrição da cultivar e os dados de produção de gemas floríferas, no presente trabalho, revelam o grande potencial de floração de 'Régis' e a satisfatória adaptação às condições edafoclimáticas da região, podendo tornar-se uma boa opção para pêssegos ultraprecoces de dupla finalidade na região de Jaboticabal. Nienow (1997) verificou que 'Aurora-1' apresentou maior número de gemas floríferas por brotação, tanto nas brotações de pernadas, como nas brotações de ramos de ano e de ramos jovens, comparativamente às cultivares Aurora2 e Tropical, sendo um dos critérios utilizados para recomendar o cultivo de 'Aurora-1' na região de Jaboticabal-SP.

No ano de 2005, o maior número de gemas vegetativas foi observado na seleção 'Jab 484', com 16,80 gemas vegetativas por $30 \mathrm{~cm}$ de ramo, a qual não diferiu estatisticamente de 'Aurora1' $(15,27)$ (Tabela 3). O menor valor foi observado em 'Régis' $(13,01)$, apesar de também não ter diferido estatisticamente de 'Jab 694' (14,81). Entretanto, no ano de 2006, todos os genótipos apresentaram valores ligeiramente maiores em relação a 2005 e 
não foram detectadas diferenças estatísticas entre si. O número de gemas vegetativas e, conseqüentemente, a produção de brotos e folhas são características importantes, pois estão relacionadas à capacidade fotossintética da planta e ao crescimento dos frutos. Na região de Jaboticabal, as folhas também exercem a importante função de sombreamento no interior da copa, minimizando os efeitos nocivos da forte insolação nos ramos principais (Pereira et al., 2002). Segundo Raseira et al. (1998), são necessárias entre 30 e 35 folhas para produzir um fruto de padrão comercial.

Nos dois anos de avaliações realizadas, a cultivar Régis apresentou a maior relação entre o número de gemas floríferas/ vegetativas (2,03 e 2,31, respectivamente), evidenciando a grande capacidade de produção de gemas floríferas desta cultivar, nas condições climáticas de Jaboticabal (Tabela 3). A abundante produção de gemas floríferas é facilmente detectada, sobretudo na metade distal do ramo misto, onde é possível observar, com freqüência, três gemas floríferas no mesmo nó. A cultivar Aurora1 apresentou relação mais equilibrada entre as gemas floríferas e vegetativas (entre 1,17 e 1,28), sendo estes valores um pouco menores do que o observado por Nienow (1997). Segundo este autor, a relação entre gemas floríferas/vegetativas é influenciada pela data da poda de renovação, pelo tipo de ramo avaliado, pela cultivar estudada e também varia de um ano para outro. No presente estudo, foi possível observar o predomínio das gemas vegetativas no primeiro terço do ramo da cv. Aurora-1. Entretanto, nos terços mediano e distal, os nós geralmente apresentam 1 gema vegetativa central flanqueada por 2 gemas floríferas, o que explica a mais equilibrada relação entre gemas floríferas/ vegetativas no ramo misto, dentre os genótipos estudados.

As seleções 'Jab 484' e 'Jab 694' apresentaram relações entre gemas floríferas/vegatativas menores do que o observado nas cultivares e não apresentaram diferenças estatísticas entre si (Tabela 3). 'Jab 484' apresentou relações entre 0,59 e 0,69, enquanto que 'Jab 694' apresentou valores entre 0,49 e 0,54, evidenciando que, para cada gema florífera, existem 2 gemas vegetativas, aproximadamente. Provavelmente, a adequação da época de poda e do sistema de condução permitirão maior eficiência no florescimento nestas seleções. Salles (2002) considerou ótimas as intensidades de florescimento, brotação e produção de frutos nestas duas seleções. Segundo este autor, 'Jab 484' possui tamanho de fruto menor que 'Biuti', mas que essa desvantagem é superada pela boa coloração da epiderme do fruto, tornando-o competitivo no mercado in natura. A seleção 'Jab 694' apresenta qualidades iguais à 'Jab 484', com exceção da coloração da película e ausência completa de auréola em torno do endocarpo, o que a credencia como fruta para compota. Também apresenta potencial por produzir frutos iguais ou maiores que 'Biuti', característica importante no rendimento industrial, na elaboração de compotas e também por ser atraente para o mercado in natura.
TABELA1- Data de aplicação da cianamida hidrogenada (DCH), número de dias para iniciar a floração (NDIF), período de floração (início, plena, final e $\mathrm{n}^{\circ} \mathrm{de}$ dias), período de colheita (início, final e $\mathrm{n}^{\circ}$ de dias) e duração do ciclo no ano de 2005 , em diferentes seleções e cultivares-copa de pessegueiros $\left(2^{\circ}\right.$ ano após o transplantio das mudas), enxertados em 'Okinawa' propagado por sementes. Vista Alegre do Alto-SP, dezembro de 2005.

\begin{tabular}{|c|c|c|c|c|c|c|c|c|c|c|}
\hline \multirow[b]{2}{*}{ Copa } & \multirow[t]{2}{*}{$\mathrm{DCH}$} & \multirow[t]{2}{*}{ NDIF } & \multicolumn{4}{|c|}{ período de floração } & \multicolumn{3}{|c|}{ período de collheita } & \multirow[b]{2}{*}{ ciclo } \\
\hline & & & $\overline{\text { início }}$ & plena & final & $\overline{\text { dias }}$ & início & final & dias & \\
\hline 'Régis' & $13 / 07$ & 14 & $27 / 07$ & $16 / 08$ & $24 / 08$ & 28 & $22 / 10$ & $02 / 11$ & 11 & 72 \\
\hline 'Jab 484' & $13 / 07$ & 14 & $27 / 07$ & $13 / 08$ & $24 / 08$ & 28 & $14 / 12$ & $28 / 12$ & 14 & 128 \\
\hline 'Jab 694' & $13 / 07$ & 14 & $27 / 07$ & $13 / 08$ & $24 / 08$ & 28 & $14 / 12$ & $28 / 12$ & 14 & 128 \\
\hline 'Aurora-1' & $13 / 07$ & 14 & $27 / 07$ & $13 / 08$ & $24 / 08$ & 28 & $22 / 10$ & $21 / 11$ & 30 & 85 \\
\hline
\end{tabular}

${ }^{1}$ ciclo $=\mathrm{n}^{\circ}$ de dias transcorridos da plena floração até a data da metade do período de colheita.

TABELA2- Data de aplicação da cianamida hidrogenada (DCH), número de dias para iniciar a floração (NDIF), período de floração (início, plena, final e $n^{\circ}$ de dias), período de colheita (início, final e $\mathrm{n}^{\circ}$ de dias) e duração do ciclo no ano de 2006 , em diferentes seleções e cultivares-copa de pessegueiros $\left(3^{\circ}\right.$ ano após o transplantio das mudas), enxertados em 'Okinawa' propagado por sementes. Vista Alegre do Alto-SP, dezembro de 2006.

\begin{tabular}{|c|c|c|c|c|c|c|c|c|c|c|}
\hline \multirow[b]{2}{*}{ Copa } & \multirow[t]{2}{*}{$\mathrm{DCH}$} & \multirow[t]{2}{*}{ NDIF } & \multicolumn{4}{|c|}{ período de floração } & \multicolumn{3}{|c|}{ período de colheita } & \multirow[b]{2}{*}{ ciclo } \\
\hline & & & início & plena & final & $\overline{\text { dias }}$ & início & final & dias & \\
\hline 'Régis' & $03 / 07$ & 23 & $26 / 07$ & $07 / 08$ & $17 / 08$ & 21 & $10 / 10$ & $30 / 10$ & 20 & 74 \\
\hline 'Jab 484' & $16 / 06$ & 18 & 04/07 & $15 / 07$ & $26 / 07$ & 22 & $08 / 12$ & $15 / 12$ & 07 & 149 \\
\hline 'Jab 694' & $16 / 06$ & 18 & 04/07 & $15 / 07$ & $26 / 07$ & 22 & $08 / 12$ & $15 / 12$ & 07 & 149 \\
\hline 'Aurora-1' & 03/07 & 18 & $21 / 07$ & $01 / 08$ & $11 / 08$ & 21 & $13 / 10$ & $30 / 10$ & 17 & 82 \\
\hline
\end{tabular}

${ }^{1}$ ciclo $=\mathrm{n}^{\circ}$ de dias transcorridos da plena floração até a data da metade do período de colheita.

TABELA 3 - Comprimento de ramos mistos depois da poda de frutificação, número de gemas floríferas por $30 \mathrm{~cm}$ de ramo, número de gemas vegetativas por $30 \mathrm{~cm}$ de ramo e relação entre gemas floríferas/vegetativas de diferentes seleções e cultivares-copa de pessegueiro, enxertados em 'Okinawa' propagados por sementes ( $2^{\circ}$ e $3^{\circ}$ anos após o transplantio das mudas). Vista Alegre do Alto-SP, 2006.

\begin{tabular}{|c|c|c|c|c|c|c|c|c|}
\hline \multirow[t]{2}{*}{ Copa } & \multicolumn{2}{|c|}{$\begin{array}{l}\text { comprimento do } \\
\text { ramo misto }(\mathrm{cm})\end{array}$} & \multicolumn{2}{|c|}{$\begin{array}{c}\mathrm{n}^{0} \text { gemas } \\
\text { floriferas } 30 \mathrm{~cm}\end{array}$} & \multicolumn{2}{|c|}{$\begin{array}{c}\mathrm{n}^{0} \text { gemas } \\
\text { vegetativas } / 30 \mathrm{~cm}\end{array}$} & \multicolumn{2}{|c|}{$\begin{array}{c}\text { relação gemas } \\
\text { floríferas/vegetat. }\end{array}$} \\
\hline & 2005 & 2006 & 2005 & 2006 & 2005 & 2006 & 2005 & 2006 \\
\hline 'Régis' & $34,06 \mathrm{a}$ & $34,34 \mathrm{a}$ & $23,23 \mathrm{a}$ & $31,50 \mathrm{a}$ & $13,01 \mathrm{c}$ & $16,98 \mathrm{a}$ & $2,03 \mathrm{a}$ & $2,31 \mathrm{a}$ \\
\hline 'Jab 484' & 38,11 a & $31,22 \mathrm{a}$ & $9,03 \mathrm{c}$ & $11,49 \mathrm{c}$ & $16,80 \mathrm{a}$ & $17,90 \mathrm{a}$ & $0,59 \mathrm{c}$ & $0,69 \mathrm{c}$ \\
\hline 'Jab 694' & $34,28 \mathrm{a}$ & $35,18 \mathrm{a}$ & $7,03 \mathrm{c}$ & $7,49 \mathrm{~d}$ & $14,81 \mathrm{bc}$ & $15,15 \mathrm{a}$ & $0,49 \mathrm{c}$ & $0,54 \mathrm{c}$ \\
\hline 'Aurora-1' & $32,87 \mathrm{a}$ & $34,83 \mathrm{a}$ & $18,53 \mathrm{~b}$ & $19,35 \mathrm{~b}$ & $15,27 \mathrm{ab}$ & $17,45 \mathrm{a}$ & $1,28 \mathrm{~b}$ & $1,17 \mathrm{~b}$ \\
\hline $\mathrm{F}_{\text {copa }}$ & $1,59^{\mathrm{ns}}$ & $1,32^{\text {ns }}$ & 196,07 ** & $137,70^{* *}$ & $11,02 * *$ & $2,89^{\mathrm{ns}}$ & 77,87 *** & $146,03^{* *}$ \\
\hline $\mathrm{F}_{\text {blocos }}$ & $0,99^{\mathrm{ns}}$ & $0,36^{\mathrm{ns}}$ & $2,94 *$ & $0,18^{\mathrm{ns}}$ & $3,80^{*}$ & $0,53^{\mathrm{ns}}$ & $1,70^{\text {ns }}$ & $0,41^{\mathrm{ns}}$ \\
\hline $\mathrm{CV}(\%)$ & 12,68 & 11,44 & 9,33 & 12,65 & 7,70 & 10,33 & 18,03 & 13,84 \\
\hline
\end{tabular}

Médias seguidas por letras distintas, na mesma coluna, diferem entre si, pelo teste de Tukey. ${ }^{*}$ significativo ao nível de $5 \%$ de probabilidade; ** significativo ao nível de $1 \%$ de probabilidade; ${ }^{\text {ns }}$ não-significativo. 


\section{CONCLUSÕES}

1- A cultivar Régis apresenta a maior produção de gemas floríferas por ramo misto, a maior relação entre gemas floríferas/ vegetativas e o menor ciclo (entre 72 e 74 dias) dentre os genótipos estudados, sendo a única classificada como ultraprecoce.

2- As seleções 'Jab 484' e 'Jab 694' apresentam ciclo mediano e comportamento fenológico idêntico, com período de colheita entre 08 e 28 de dezembro.

3- A cultivar Aurora-1, quando cultivada na região de Jaboticabal-SP, apresenta relação de gemas floríferas/vegetativas próxima a 1, ciclo entre 82 e 85 dias, e pode ser classificada como bem precoce.

\section{AGRADECIMENTOS}

Os autores agradecem à FAPESP, pelo apoio financeiro (Processo ${ }^{\circ}$ 04/12110-6), e ao Sr. Valdenir Rossi, proprietário da Fazenda Santa Alzira (Vista Alegre do Alto-SP), pela concessão da área experimental, de máquinas, equipamentos e mão-de-obra para a condução do experimento.

\section{REFERÊNCIAS}

CATI. Mapa da Agricultura Paulista. Projeto Lupa, pêssego, 1997. Disponível em: <http//www.cati.sp.gov.br/servicos/mapa/ culturas/pessego.htm $>$ Acesso em: 10 out. 2002.

BARBOSA, W.; OJIMA, M.; CAMPO DALL'ORTO, F.A.; MARTINS, F.P. Época e ciclo de maturação de pêssegos e nectarinas no Estado de São Paulo. Bragantia, Campinas, v.49, n.2, p.221-226, 1990.

BARBOSA, W.; OJIMA, M.; CAMPO DALL'ORTO, F.A.; RIGITANO, O.; MARTINS, F.P.; SANTOS, F.P.; CASTRO, J.L. Melhoramento do pessegueiro para regiões de clima subtropical-temperado: realizações do Instituto Agronômico no período de 1950 a 1990. Campinas: Instituto Agronômico, 1997. 22p. (Documentos IAC, 52).

BARBOSA, W.; POMMER, C.V.; RIBEIRO, M.D.; VEIGA, R.F. de A.; COSTA, A.A. Distribuição geográfica e diversidade varietal de frutíferas e nozes de clima temperado no Estado de São Paulo. Revista Brasileira de Fruticultura, Jaboticabal, v.25, n.2, p.341344,2003

NIENOW, A.A. Comportamento morfológico, fenológico e produtivo de cultivares de pessegueiro (Prunus persica (L.) Batsch), submetidos à poda de renovação após a colheita, na região de Jaboticabal-SP. 1997. 171f. Tese (Doutorado em Agronomia) - Faculdade de Ciências Agrárias e Veterinárias, Universidade Estadual Paulista, Jaboticabal, 1997.
OJIMA, M.; CAMPO DALL'ORTO, F.A.; BARBOSA, W.; MARTINS, F.P.; SANTOS, R.R.; RIGITANO, O. 'Aurora-1' e 'Aurora-2': novas cultivares de pêssego doce de polpa amarela. In: CONGRESSO BRASILEIRO DE FRUTICULTURA, 10., 1989, Fortaleza. Anais... Fortaleza: SBF, 1989. p.422-425.

OJIMA, M.; CAMPO DALL'ORTO, F.A.; BARBOSA, W.; MARTINS, F.P.; CASTRO, J.L.; SANTOS, R.R.; SABINO, J.C.; BOVI, V.; RIGITANO, O. 'Régis' - nova cultivar de pêssego para mesa e conserva. Revista Brasileira de Fruticultura, Cruz das Almas, v.13, n.3, p.293-296, 1991.

PEREIRA, F.M.; NACHTIGAL, J.C.; ROBERTO, S.R. Tecnologia para a cultura do pessegueiro em regiões tropicais e subtropicais. Jaboticabal: Funep, 2002. 62p.

PEREIRA, F.M.; MAYER, N.A. Pessegueiro: tecnologias para a produção de mudas. Jaboticabal: Funep, 2005. 65p.

RAIJ, B. Van.; CANTARELLA, H.; QUAGGIO, J.A.; FURLANI, A.M.C. Recomendações de adubação e calagem para o Estado de São Paulo. Campinas: IAC; 1996. (Boletim Técnico, 100).

RASEIRA, A.; PEREIRA, J.F.M.; MEDEIROS, A.R.M.; CARVALHO, F.L.C. Instalação e manejo do pomar. In: MEDEIROS, C.A.B.; RASEIRA, M. do C.B. A cultura do pessegueiro. Brasília: Embrapa SPI; Pelotas: Embrapa CPACT, 1998. p.130-160.

SACHS, S.; CAMPOS, A.D. O pessegueiro. In: MEDEIROS, C.A.B.; RASEIRA, M. do C.B. A cultura do pessegueiro. Brasília: Embrapa SPI; Pelotas: Embrapa CPACT, 1998. p. 14-19.

SALLES, L.C. Comportamento e seleção de plantas de pessegueiro [Prunus persica (L.) Batsch] originadas de polinização aberta da cultivar Biuti. 1997. 113f. Dissertação (Mestrado em Agronomia) - Faculdade de Ciências Agrárias e Veterinárias, Universidade Estadual Paulista, Jaboticabal, 1997.

SALLES, L.C. Comportamento e seleção de plantas de pessegueiro [Prunus persica (L.) Batsch] originadas de polinização aberta da cultivar Biuti, para a região de JaboticabalSP. Jaboticabal: FCAV-UNESP, 2002. (Relatório final FAPESP).

VOLPE, C.A. (Coord.). Estação agroclimatológica: balanço hídrico de Jaboticabal (período 1971-2000). 2000a. Disponível em: <http://www.exatas.fcav.unesp.br/estacao/est_balanco.htm>. Acesso em :13 fev. 2007

VOLPE, C.A. (Coord.). Estação agroclimatológica: resenha meteorológica do período 1971-2000. 2000b. Disponível em: $<\mathrm{http}$ / /www.exatas.fcav.unesp.br/estacao/est_resanha.htm>. Acesso em: 13 fev. 2007. 